\title{
A 2009 Perspective of HR Practices in Australian Mining
}

\begin{abstract}
Purpose - The purpose of this paper is to explore the idea of how HR professionals undertake strategic, management and operational roles in mining organisations during varying economic cycles. The discussion is primarily set in the Western Australian context.

Design/Methodology/Approach - A review of the relevant literature, an overview of mining industry trends in Australia and an examination of HR issues in the mining industry, provide the background for developing a case for a strategic approach using HR practices to address challenges.
\end{abstract}

Findings - A 5-point model for effective delivery of HR in the mining industry is proposed as a means of overcoming environmental discontinuities.

Research limitations/implications - Whilst an extensive list of research in the mining industry, is not cited, given that the mining industry tends to operate globally and HR departments source and deploy professional staff on a global basis, the implications for future research are more extensive than limiting.

Practical implications - Contrary to many current practices used in mining organisations, suggestions are made regarding specific approaches that can be promulgated to change HR policies and procedures to assist overcoming, or mitigating, bust cycle issues in the industry.

Originality/value - Mining companies need a well organised plan if they are to balance out the extremes of the industry's boom/bust cycles. The model in this paper, establishing strategic implementation strategies for HR policies and procedures, provides a direct approach to business improvement and a direct link between corporate and mine-site HR issues.

Keywords: Mining strategy; HR objectives; HR accountability; HR implementation; Western Australia.

Article type: Conceptual Paper

Journal: Journal of Management Development. 


\section{A 2009 Perspective of HR Practices in Australian Mining}

\section{Introduction}

Although mining organisations operate with a finite resource, often in remote locations, require specialised skills, with high capital intensity and are subject to political, social and environmental global issues, there are many internal and external factors that are common with other industries and contribute to an organisation's success. Hills (2008) listed four main internal influences on businesses:

- The core strategy of the business.

- The quality of the organisation's people and their ability to deliver the strategy.

- The quality of leadership in the organisation.

- The quality of execution of the policies, processes and projects needed to meet strategic goals.

All four influences involve people. Therefore, as a mining organisation's human resource (HR) function is about people management, its HRM division has the ability and responsibility to make a significant contribution to the organisation's success at strategic, management and functional levels.

At the end of 2008, the Western Australian (WA) mining and petroleum industries contributed $89 \%$ (AUD $\$ 74.65$ billion) toward total WA merchandise exports, and $41 \%$ of Australian merchandise exports (WA DMP, 2008). The WA mining industry contributes significant government royalties and provides direct employment to around 70,000 people (Figure 1) and indirect employment to around 150,000 (CME, 2006). The WA resource sector, therefore, is of significant importance to both the Australian and Western Australian economies.

Take in Figure (1)

The mining industry is among the most technologically advanced of all heavy industries. Nevertheless, it relies on both employees and contractors (Figure 2); in Ednie's (2004) terms, people to drive, create and shape the operations and technologies that sustain production. Research by the Canadian Mining Industry Training and Adjustment Council (MITAC) identified that, although the workforce has fluctuated over the past decade, productivity has continuously increased. Furthermore, their research indicates that a worker in today's mining industry must be more versatile, better educated and better trained than ever before. 
In Prospecting the Future - Meeting Human Resources Challenges in the Canadian Minerals and Metals Industry, research by MITAC (2005) indicated the following key HR challenges facing the Canadian industry:

- aging and retirement of workforce;

- lack of labour force diversification;

- competition for workers from other industries;

- poor industry image;

- volatile business cycle;

- changing skill requirements; and

- need for national occupational standards and certification.

At the time, these HR issues were equally applicable to the Australian resource sector and continue as on-going challenges.

Fast forward five years to 2009, and the global economic landscape was dramatically different. The resource sector had been hit hard with plunging commodity prices and falling demand. Consequently, most HR challenges identified in 2004 as being relevant during boom years became even more critical in the bust year.

Taking cognizance of the gloomy economic landscape of 2009, how an organisation's HR functions can effectively contribute to an organisation's performance is discussed in this paper, with particular reference to the Western Australian mining industry.

\section{Current HRM Challenges}

\subsection{Mining Industry Trends}

Against a background of exceptional uncertainty, prospects for world economic growth in the short term have been revised down markedly and the outlook is subject to considerable downside risks (ABARE, 2008). In 2008 it was predicted that the global financial crisis would weaken world economic growth significantly in the short term, to around 2.5\% in 2009 (ABARE, 2008) (Figure 3). Economic activity was forecast to contract in a number of OECD countries during 2009, before a gradual recovery in late 2009, whilst adverse impacts on emerging economies were predicted to be less significant (ABARE, 2008). Australian economic growth was forecast to be $2.0 \%$ during 2009 (ABARE, 2008) with some government statements leading to even lower growth forecasts. Economic growth slowed to less than 1\% in early 2009 but rallied later in the year to record an overall growth of $2.7 \%$ for the year (ABC News, 2010)

Take in Figure (3)

The advent of the global financial crisis meant mining organisations had to reduce staff numbers in order to reduce operating costs, even though there was a general expectation 
they sustain production levels or grow businesses. The reducing availability of capital in the market also curtailed many mining companies' growth plans.

The Australian economy is heavily reliant on the resource sector; employing tens of thousands of people and contributing billions of dollars in taxes and mining royalties to the government coffers. Therefore, the economic slowdown was expected to have a significant affect on the Australian mining industry with associated heavy job losses and reduced government revenue.

Australia's main customers for energy exports are Japan and Korea, and China and Japan for mineral exports (Figure 4). As volatility in commodity prices was likely to continue in the short-term, mainly as a result of increased uncertainty about world economic growth and, hence, world commodity demand (ABARE, 2008), Australia's relationship with these customers became even more important.

Take in Figure (4)

Attracting new entrants (professional and trade) to the mining industry has always been challenging. The combined influence of working away from home and poor industry image has meant that other industries have a larger pool of prospective employees from which to recruit. Consequently, the mining industry has experienced an aging workforce, with flow on effects in knowledge management, supervisor training, leadership identification etc.

In September 2008, the Canadian Mining Industry Human Resources (MIHR, 2008) Council presented what they considered to be the top five HR challenges facing the Canadian mining sector: viz., aging workforce; growth of the sector; significant recruitment and retention challenges; lack of a skills recognition system and limited workforce mobility; and anticipated demand for 92,000 additional workers across all occupational groups by 2016. In Western Australia, the projected AUD \$43 billion development cost Gorgon gas project alone (Klinger, 2009, p.1), set to start immediately, will require "up to 10,000 workers employed during the project's construction phase, followed by 3,500 permanent operational jobs".

Technological advancements in the mining industry continue as organisations strive to improve metal recoveries and make lower grade deposits economical. Therefore, today's mining industry requires skilled workers who can integrate sophisticated equipment and leading edge technology in every aspect of mining operations if they are to remain competitive and sustainable in any economic circumstance.

Considering the challenging opportunities in light of the economic market, it is critical that mining organisations structure their business to 'get more out of what they already have'. That is, mining companies must do more with their existing financial, technological and human resources (Watson, 2008).

\subsection{Australian Mining HR Issues}

During the 10-year period 1999 to 2008 the value of the Western Australian mineral and petroleum industry grew on average $18 \%$ per annum (WA DMP, 2008). Associated with 
this growth, the WA Chamber of Minerals \& Energy (CME, 2006) identified a number of HR strategic issues for the WA resource sector - skills shortage, employee attraction and retention, flexible workplace practices, indigenous employment opportunities and community-regional services.

Mining industry demographics show that mass retirements will happen over the next decade or so and a large number of skilled staff will be required to design and operate mining operations.

Over the past five years, the skilled labour shortages in Australia have required the increased use of foreign skilled labour (AMMA, 2009). As a result of the global economic crisis, the Australian government has taken steps to reduce the number of foreign workers entering Australia. This will further exacerbate the shortage of skilled professionals required to sustain and grow the industry in the future.

Even though the number of potential applicants has increased recently, the war for talent remains. Companies, therefore, must initiate competitive strategies to attract and retain the talent they will need for the future. Hathaway-Smith (2009) notes that a key priority for employees during 2009 was to develop internal talent and aid staff retention. Furthermore, Hathaway-Smith (2009) noted that during 2009 employers must recognise that up-skilling the workforce was now more important than ever for industries to remain competitive. Syed (2007) discussed workforce diversity, the ageing workforce, generational differences, talent identification and retention in an era of skills shortage. He noted the need to motivate the workforce and increase the skills base in the organisation for it to successfully compete globally. Additionally, Wilson (2008, p.5) argued that "managing talent is the most challenging issue facing employers in Europe going forward to 2015"; a situation replicable in the southern hemisphere.

During boom times, mining companies find it difficult to attract staff, even though huge salaries are on offer. This highlights a challenge quite unique to mining; viz., attracting highly skilled people to the remote location of most mine sites (Ednie, 2004). This issue will remain into the future, particularly with Generation $Y$ persons entering the job market and not being prepared to travel (Tulgan and Martin, 2001).

The global financial crisis created considerable uncertainty in the mining industry. In addition to the recruitment and retention issues, organisations were faced with trying to keep staff motivated at a time when more job losses were predicted and budgets became getting tighter.

The AMMA noted in its Activities Report (AMMA, 2009) that there is an inevitable shift towards national health and safety regulations. This can be expected to affect how mining companies structure some job roles in the future.

The mining sector was a major adopter of Australian Workplace Agreements (AWAs). Whilst this helped change the mining industry from a culture of confrontation and divisiveness to a workplace culture of collaboration where choice and flexibility are paramount, this did little to protect workers during the downturn of 2009. The Australian Labour Government was elected at the end of 2007 with a mandate for a new policy agenda regarding industrial relations. The full raft of industrial relations' changes will doubtless impact on mining employment conditions and as the IR pendulum has swung recently the issue of workplace relations will remain high on 
resource company agendas. The importance of having a robust workplace relations system in place and measures to address capacity constraints caused by infrastructure bottlenecks and skills shortages is highlighted by the AMMA (2009). However, it seems that in practice SHRM has something of a blind spot in relation to industrial relations and does not pay as much attention to it as is necessary.

\section{Addressing the Challenges}

\subsection{A Strategic Approach}

During 2008, global research by McKinsey (Astor Levin, 2009) indicated that HR strategy-related decisions by organisation's HR functions aim to improve efficiency or productivity (56\%), achieve cost savings $(25 \%)$ or drive revenue growth $(19 \%)$ within the organisation. However, to be truly strategic, HR needs to understand the business strategy and its implications for the function (Polyhart, 2006), as well as knowing the strengths and weaknesses of the people and leaders who are delivering that strategy (Hills, 2008).

Strategic human resource management (SHRM) emphasises the need for HR plans and strategies to be formulated within the context of overall organisational strategies and objectives, and to be responsive to the challenging nature of the organisation's external environment (Nankervis et al., 2008).

In the current economic environment, it is argued that a strategic approach to the management of an organisation's human capital is required more than ever. Therefore, as proposed by Uysal (2008), HR professionals should have three major content areas to effectively implement SHRM:

- traditional HR functional content (staffing, compensation, etc.);

- $\quad$ change management or leadership skills (communication, negotiation, etc.); and

- business skills (ability to understand business language and function effectively as a business partner).

\subsection{Effective Practices - What Works?}

Alignment between the business and human resource management (HRM) strategy is the key factor of success for organisations according to Wylie (2005) and Wang and Shyu (2008). These researchers found that when the HRM strategy and business strategy were aligned, the effectiveness of HR practices and organisational performance were better than in those organisations that were not aligned. Research based in Australia (Zheng, Rolfe, DiMilia and Bretherton, 2007) also linked strategic HR to the organisation's overall strategies and identified the impact of strategic HR on organisational performance.

A more recent study (Uysal, 2008) also explored the relationship between HR practices and firm performance. The study found that HR practices have an impact on firm performance and significant and positive relationships among HR practices and firm performance. Staffing, training, compensation and promotion were found to be 
significantly and positively related to both the organisational and market performances of firms.

Astor Levin (2009) surveyed a number of Australian business leaders about the HR trends, challenges and priorities they face in 2009; three broad priorities were identified:

- Retention Strategies.

- Downsizing or 'Right Sizing' activity will continue.

- Organisations need to continue to invest in their people.

Key action points for HR Professionals from Price Waterhouse Coopers 11 th Annual Global CEO Survey (PWC, 2009) included:

- demonstrating the link between people and value;

- articulating the impact HR policies and procedures have on overall business strategy and demonstrating, in financial terms, how the people strategy supports the business;

- taking responsibility for effectively measuring the return on investment delivered by the people strategy; and

- being seen as more than a business partner and more as a key enabler and 'steward' of the organisation's key people.

Human capital can create competitive advantage as it improves learning through doing and thereby reduces firm's costs (Uysal, 2008). Therefore, HR plays a significant role in managing a firm's human capital, which is their employees' collective knowledge, skills and abilities. Other kinds of capital are generally readily accessible and technology is easily copied. Therefore, for all intents and purposes in today's knowledge-based economy, how a company manages its human capital is the remaining source of enduring competitive advantage (Hebert, 2004; Kulik and Bainbridge, 2006).

Companies able to communicate effectively, significantly outperform their peers. Highly effective companies promote two-way communication between senior leaders and employees, and work through frontline managers and supervisors to reinforce key messages, gather employee input and establish individual objectives that align with corporate goals (Finney, 2008). Therefore, a communication plan on how to deliver HR initiatives would have been beneficial in the 2009 environment.

\subsection{Application to the Mining Industry}

Mineral commodities are historically volatile, and boom and bust periods within short timeframes are not uncommon. The traditional mining company approach in periods of declining commodity demand has been to slash staff to reduce costs. However, with the advent of SHRM the current challenge for HR professionals is to guide their organisation in managing costs without damaging the organisation's competitive positioning, critical services or growth prospects.

In periods of capital constraint, reducing demand and shrinking margins as occurred in 2008 and early 2009, one simple strategy for an organisation to increase their effectiveness is to do more with whatever existing assets and people they have. 
Therefore, mining organisations must identify and retain the talent within the firm whilst also training and developing that talent to lead the firm into the next boom.

In a downturn economy, HR practitioners need to be emphasising to their organisations that it is necessary to do the right thing for the long-term value and sustainability of the business. This includes recognising the link between leadership and performance, and hence ensuring that leadership talent is retained, developed and, most importantly, allowed to lead through the tough times (HRL, 2009).

Mining organisations must manage their human capital to create a competitive advantage. Therefore, a goal for HR during troubled times is to harness corporate intelligence, to ensure that mining organisations do not just downsize but they are actually right sizing.

In response to the challenging demographics of an aging mining workforce, organisations must launch succession planning and professional development programs or look to recruit the right skill sets and experience.

Even though the mining industry was in a downturn, there will be a recovery and organisations need to be in a position to capitalise when the market improves. Mining organisations need to look at exemplar peers in order to identify strategies to attract and retain key personnel. One such company is Badger Mining Corporation, that was named in 2006 the "Best Small Company to Work for in America" following results from employee surveys. Reasons for their success included:

- strong lines of communication;

- $\quad$ work culture with a family-orientated atmosphere;

- self-directed work teams have company decision-making responsibilities;

- high level of community involvement; and

- employee benefit offerings such as full medical, dental, profit sharing and wellness programs.

Local Australian mining companies could have reduced some of the anxiety and uncertainty that surrounded employment issues during the downturn by considering these factors.

\section{Discussion of Decision-Making \& Ownership}

Considering the environmental analysis summarised previously in this paper, the key HR challenges facing the Australian mining industry, and potential management actions to overcome them, are suggested below:

\subsection{A Greying Workforce - Replacing Retirees}

A large proportion of the current mining workforce is in the 50-years old bracket and will be reaching retirement age over the next decade. Associated with this exodus of employees will be the loss of specialist knowledge associated with working in the 
industry. HR practitioners will need to put in place processes to make sure that valuable knowledge is preserved and passed on to younger workers.

A key consideration with this issue will be that exiting Baby Boomers will be replaced by Generation $X$ and $Y$ employees who have different values and ideals on what an employment contract should look like (Tulgan and Martin, 2001). Therefore, employment contracts and working environments for these new entrants will need to be considerably different to those of Baby Boomers if mining companies are to have success in replacing retiring employees (Tulgan and Martin, 2001).

\subsection{Investing in Human Capital - Retention of Key Talent}

If mining companies are to be well equipped to take advantage of the next growth cycle then they must retain and develop their key talent. Firstly companies will need to identify their key talent and then determine strategies to keep this talent. In an industry that is cyclical in nature, HR professionals will need to generate a culture of loyalty in order to keep key talent even though history shows that during downtimes mining companies traditionally shed staff.

As specialist skill sets remain in demand, the challenge for HR has shifted from the attraction of skilled personnel to the protection of existing labour forces. Strategies for retaining key staff include reviews of remuneration and benefits packages (Janas, 2009), job design and career management/planning (Wingfield, 2009), and flexible working arrangements (Patton, 2008).

As Astor Levin (2009) comments "a balanced people strategy is needed, including fair terms and conditions, competitive salaries, flexible work practices and learning and development opportunities amidst a strong, vibrant and healthy workplace culture."

\subsection{Skills Shortage - Growing the Talent Pool}

The industry requires skilled workers to efficiently operate their mines. Therefore, recruitment is a key challenge, particularly when the mining industry is competing against other more attractive industries for skilled workers.

Attractive packages to persuade workers to join the mining industry need to be developed. Total remuneration will need to consider benefits in addition to salary such as reduced rosters (more time at home), training to broaden skills and mining camps with more of the comforts of home.

During the boom there was global movement of skilled workers, with Australians viewed as highly valuable staff. One strategy to improve recruitment and retention rates may include targeting ex-pat Australians to return home.

There is still limited awareness of the diverse employment opportunities available and the highly specialist skills required to work within the mining industry. Recruitment strategies should take into consideration the requirement to educate young people of these opportunities.

With the increasing unemployment rate, the pool of skilled talent has increased; however, it would be best for mining companies to use the opportunity to recruit those 
skills and talents that they need to meet the business objectives rather than just any available person. Thus, recruitment will become much more strategic and targeted.

\subsection{Up-skilling the Workplace - Training \& Development}

The knowledge gap that will be created once experienced personnel start retiring will need to be managed, either through recruiting other skilled workers or by training and developing existing talent.

Training and development of existing staff will need to be maintained as the mining industry continues to implement new technologies. For example, the introduction of remote mining techniques (such as autonomous haul trucks) will reduce the safety risk; however, the level of training required for truck drivers will considerably increase.

Australia's main export customers for resources are Japan, China and Korea (Figure 4). It is likely that individuals with experience in dealing with these countries, and can speak the local language, will become highly sought. Alternatively, training and development programs structured around understanding the resource sector customers may be advantageous in seeking a competitive advantage.

\subsection{Optimising Human Capital - Keeping Staff Motivated}

Downsizing in the mining industry continued during 2009 as mining companies felt the brunt of sustained lower commodity prices and reduced demand. The threat of job losses surrounding existing mining workforces provided a challenge for HR in maintaining staff morale whilst also motivating employees to 'go the extra yard' for the organisation.

Mining companies needed to communicate the reasons for staff redundancies and budget cutbacks and engage their staff in decisions going forward in order to generate trust amongst their remaining workforce so that they could remain competitive once the economy improved. There was a need for HR to work on making the workplace vibrant and with a culture that encouraged employee commitment.

For example, BHP Billiton's Human Resource Strategy is outlined in their Sustainability Report (BHPB, 2008). They state that "people are the foundation on which all activities rely and to be successful, we must identify, recruit, train, develop and retain a talented, diverse, mobile and motivated workforce." BHP Billiton's HR Strategy connects their values, culture and business requirements to the way they manage their people and assess their HR performance.

The question on who should own the HR function is open to debate. Over the past decade mining organisations have outsourced many functions that were traditionally provided by corporate level - such as engineering design, IT support, recruitment and training. Largely, this structural re-organisation was driven by cost reduction objectives; however, there is an element of good business practice in the move to outsource noncore functions. The argument revolves on how much of the business can be left to other organisations that have their own objectives? HR has not been immune to downsizing, with many mining companies now containing very small HR departments whilst outsourcing many traditional HR functions. 
Therefore, in the current market it is very unlikely that HR departments will increase; therefore, they will generally contain a small team of professionals. The most appropriate process will be for HR departments to provide the strategic HR objectives in order for mining companies to meet the business goals whilst also providing clear guidelines on what HR functional support is required by line managers as suggested by Kulik and Bainbridge (2006). Often line managers are in the best position to plan and deliver HR objectives for their teams, however, as they are not trained in HR they require well written and concise instructions as well as access to HR professionals for guidance in order to deliver the strategic intent of the HR policies.

The case has been put forward for a commitment to employee development and retention during troubled times as investment in human capital is fundamental to organisational success. As there will be strong opposition from an organisation's financial department to reduce the funding allocated for HR functions, the overall ownership of the organisation's HR Strategy must be retained at a corporate level. HR practitioners in the corporate office need to communicate the business benefits of good $\mathrm{HR}$ at board level and must measure and monitor performance indicators to justify maintaining HR expenditure.

In summary, the delivery of HR practices should be by joint decision-making between corporate and operations, and between HR practitioners and line managers. However, corporate HR departments must own and be accountable for the organisations' HR Policy, Plans and Procedures but also provide line managers the necessary training, guidance tools and 'help desk' to deliver HR programs effectively.

\section{Summary \& Conclusion}

Organisations generally have three types of capital available to sustain and grow their operations - financial, technological and human. In the current market, financial capital is difficult to access, and research and development into further technological advancements is also cost constrained. Potentially, this leaves an organisation's human capital as the one item that an organisation can manage and mould to provide a competitive advantage that will ensure the survival of the organisation and also set the organisation up for success when the commodity cycle eventually turns full cycle again. In this paper it has been argued that the human resource function is vital to the effective management of human capital. A structured and strategic investment in an organisation's people will provide the foundation for a mining company to lead the industry through into the next decade.

Undoubtedly, employers now have the upper hand in the war for talent; however, as Humber (2009) states, "employers should not take a respite from HR programs as the business case for good HR was not solely built on competing for talent". Good HR is also about motivating employees, keeping them engaged and increasing productivity. Solid HR practices contribute to the bottom line, regardless of economic conditions (Humber, 2009).

The key HR challenges facing the West Australian mining industry during 2009 and the next few years are considered to be:

- A Greying Workforce - Replacing Retirees 
- Investing in Human Capital - Retention of Key Talent

- Skills Shortage - Growing the Talent Pool

- Up-skilling the Workplace - Training \& Development

- Optimising Human Capital - Keeping Staff Motivated

HR strategies to tackle the above challenges have been presented in this paper.

Western Australian commodities make up a significant portion of global commodity trade (Figure 5). Western Australia's sophisticated mining techniques, highly skilled workforce, reliable production, high quality commodities and low sovereign risk mean that Western Australia is in an excellent position to capitalise when the global economy fully recovers. Effective management of the mining industry's human capital by industry bodies and tertiary institutes also will provide a competitive advantage over other countries.

Take in Figure (5) 


\section{Reference List}

ABARE (2008), Australian Commodities - December Quarter 2008, www.abare.gov.au (accessed 23 April 2009).

ABC News (2010), Economic growth gives RBA 'carte blanche' to raise rates, March, http://www.abc.net.au/news/stories/2010/03/03/2835165.htm (accessed 11 May 2010)

AMMA (2009), "Activities Report 2008 - Voice of Employers in the Resources Sector", Australian Mines \& Metals Association, www.amma.org.au (accessed September 18 2009).

Astor Levin (2009), "HR Priorities in 2009: The Landscape Continues to Change", www.astorlevin.com (accessed 23 April 2010).

BHPB (2008), “BHP Billiton Full Sustainability Report 2008”, BHP Billiton, www.bhpbilliton.com (accessed 9 March 2009).

CME (2006), "Australia Strategic Management Issues Facing WA in 2007 and Beyond". Chamber of Minerals \& Energy, Western Australia.

Ednie, H. (2004), “Innovative Solutions for Mining's Human Resource Challenges”, CIM Bulletin, Vol. 97 No. 1076, p. 9.

Finney, J. (2008), “Six Secrets of Top Performers”, Communication World, Vol. 25 No. 3, p. 23.

Hathaway-Smith, P. (2009), “HR Resolutions 2009”, Personnel Today, Jan. 13, p. 6.

Hebert, P. (2004), "Prospecting the Future”, CIM Bulletin, Vol. 97 No. 1082, p. 32.

Hills, J. (2008), “Need to Know: Internal Influences”, Personnel Today, June 3, p. 32.

Humber, T. (2009), “Don't Abandon Solid HR Practices”, Canadian HR Reporter, Vol. 22 No. 3, p. 22.

HRL (2009), “2009 - How HR Can Revive to Survive”, Human Resources Leader, www.humanresourcesmagazine.com.au (accessed 21 August 2009).

Janas, K. M. (2009), “Keeping good people in bad times”, Workspan, Vol. 52 No. 11, pp.66-71.

Klinger, R. (2009), “Gorgon bonanza to trigger new boom”. The West Australian, Tuesday, September $15^{\text {th }}$, p. 1.

Kulik, C. T. and Bainbridge, H. T. J. (2006), "HR and the line: The distribution of HR activities in Australian organisations", Asia Pacific Journal of Human Resources, Vol. 44 No. 2, pp. 240-256.

Mining Industry Human Resources Council (MIHR) (2008), National Strategy Overcoming HR Challenges in the Canadian Mining Industry (September 2008). www.mihr.ca (accessed 21 August 2009).

MITAC (Mining Industry Training and Adjustment Council) (2005), "Prospecting the Future - Meeting Human Resources Challenges in the Canadian Minerals and Metals Industry". www.prospectingthefuture.ca (accessed 21 April 2009). 
Nankervis, A., Compton, R. and Baird, M. (2008), Human Resource Management: Strategies $\mathcal{E}$ Processes, Cengage Learning Australia Pty Ltd, Australia.

Patton, Z. (2008), “Free on Friday”, Governing, Vol. 22 No. 3, pp. 38-43.

Polyhart, R. E. (2006), "Staffing in the 21 century: New challenges and Strategic. Opportunities", Journal of Management, Vol. 32 No. 6, pp. 868-897.

PWC (2009), “Global CEO Survey - the importance of Human Resources”, Price Waterhouse Coopers. www.pwclegal.com.au (accessed 9 March 2010).

Syed, J. (2007), "Redesigning skill policy for an ageing Australia”, International Journal of the Humanities, Vol. 4 No. 8, pp. 39-52.

Tulgan B. and Martin C. A. (2001), Managing Generation Y: Global Citizens Born in the Late Seventies and early Eighties, Hrd Press, Amherst MA.

Uysal, G. (2008), "Relationship among HR and Firm Performance: A Turkey Content", The Journal of American Academy of Business, Vol. 13 No. 2, p. 77.

WA DMP (2008), “The Importance of Western Australian Resources Industry Continues to Grow", Western Australian Department of Mines \& Petroleum. www.dmp.wa.gov.au (accessed 23 August 2009).

Wang, D. and Shyu, C. (2008), "Will the Strategic Fit Between Business and HRM Strategy Influence HRM Effectiveness and Organisational Performance?", International Journal of Manpower, Vol. 29 No. 2, p. 92.

Watson, A. (2008), "Incorporating Sustainability into Mining Services", Engineering and Mining Journal, Vol. 209 No. 7, p. 106.

Wilson, F. (2008), "Meeting the challenges of global resourcing", Strategic HR Review, Vol. 7 No. 2, pp. 5-10.

Wingfield, C. (2009), "Retaining key employees in a tough economic environment", The Tax Adviser, Vol. 43 No. 3, pp. 176-179

Wylie, J. (2005), “The Ideal Antidote to Shrinking Margins - Doing More with Your Existing Assets and People", Engineering and Mining Journal, Vol. 206 No. 6, p. 58.

Zheng, C., Rolfe, J., DiMilia, L. and Bretherton, P. (2007), “Strategic people management of coal mining firms in Central Queensland", Management Research News, Vol. 30 No. 9, pp. 689-704. 
Figure 1 - WA Mining Employment 1987 - 2008 (WA DMP, 2008)

Mining Employment 1987 - 2008

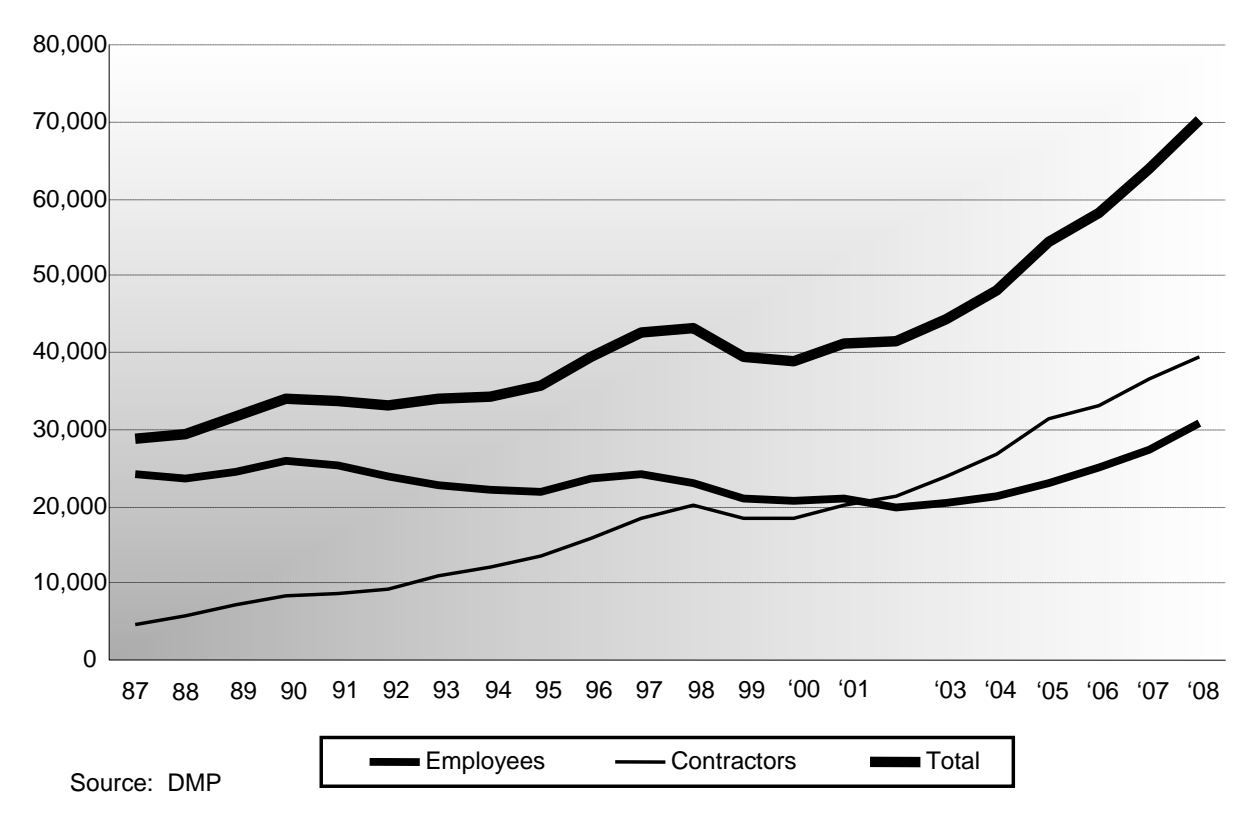


Figure 2 - WA Mining Employment Jan-03 to Jan-09 (WA DMP, 2008)

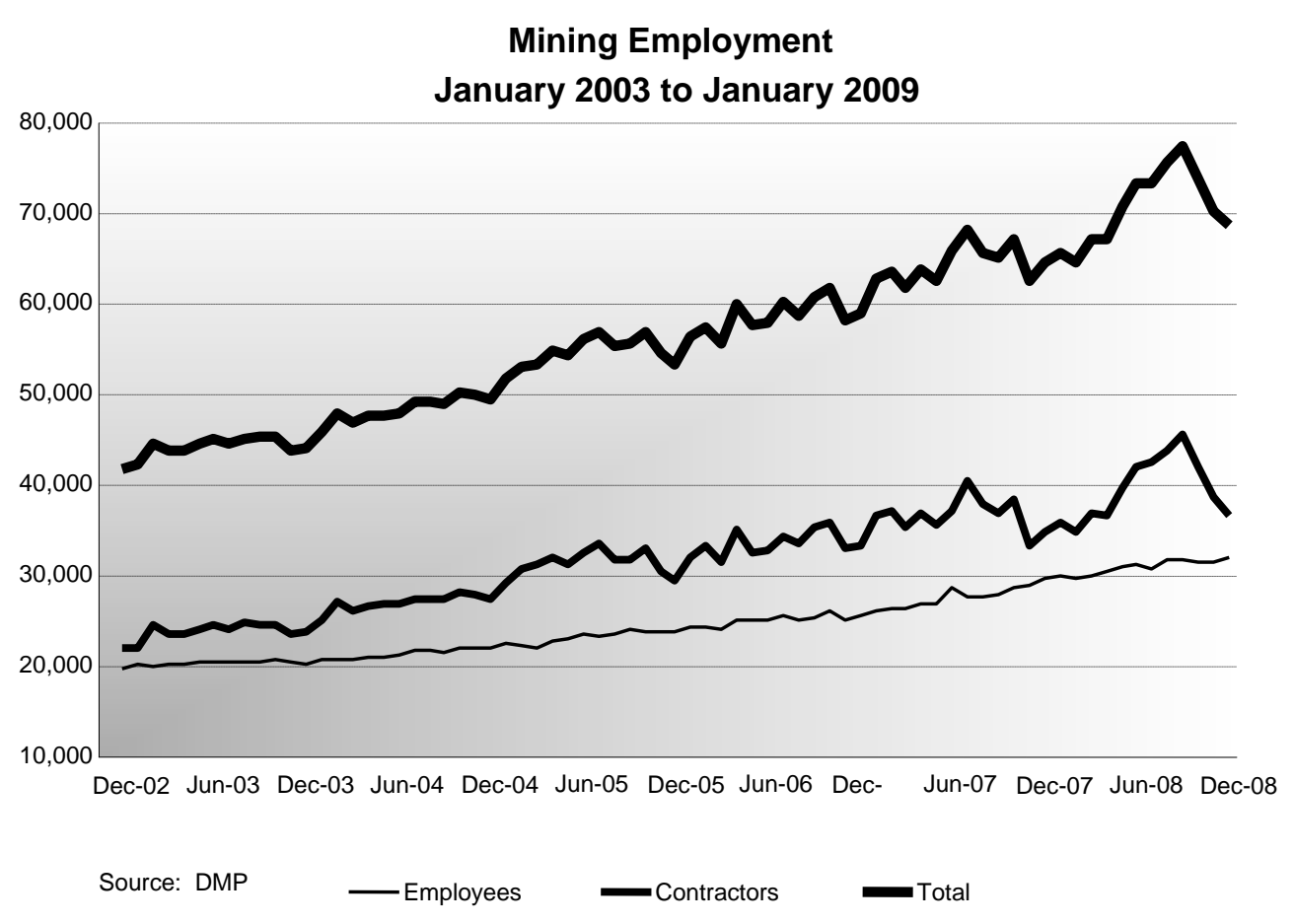


Figure 3 - Economic Growth Forecasts (ABARE, 2008)

World economic growth

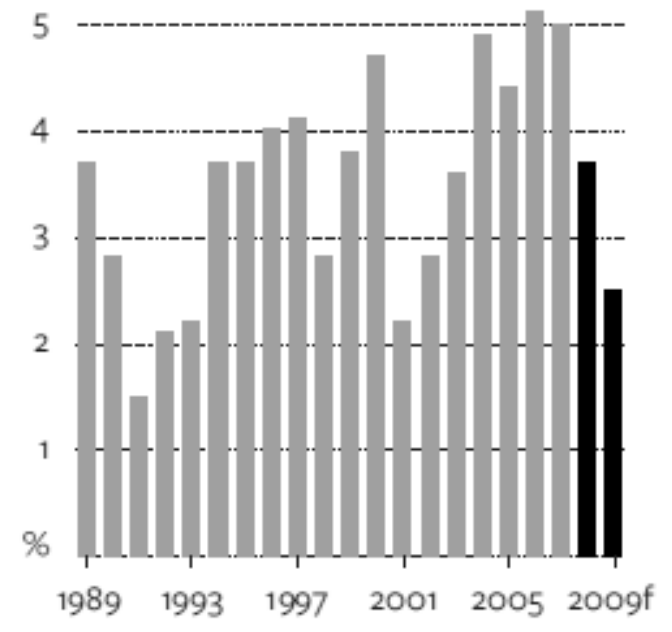

Regional economic growth

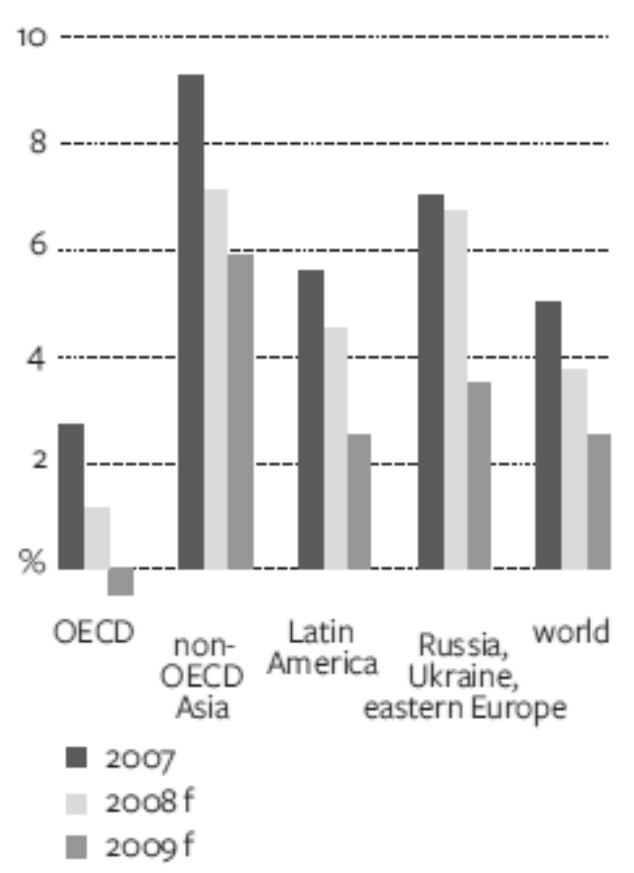


Figure 4 - Australian Export Markets 2007-08 (ABARE, 2008)

Markets for Australian energy exports, 2007-08

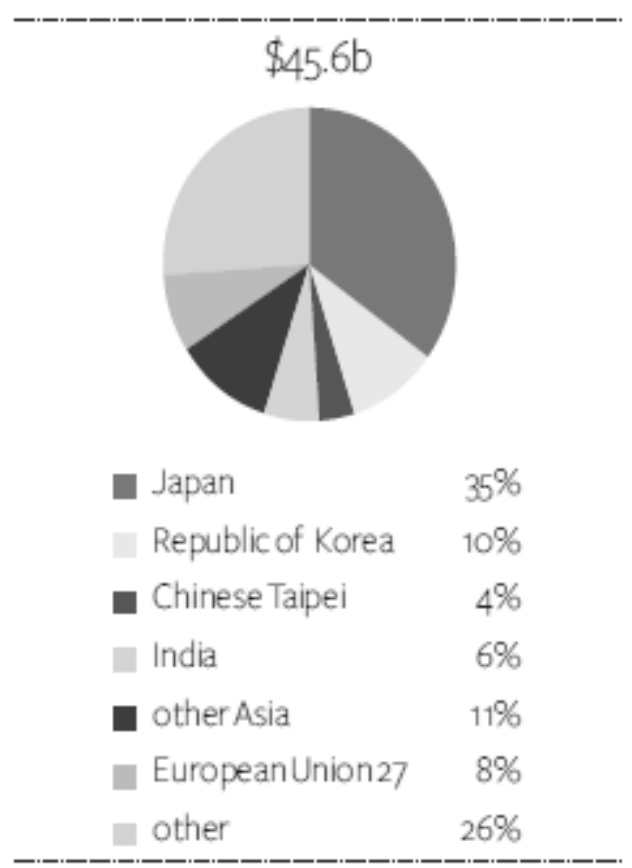

Markets for Australian mineral exports, 2007-08

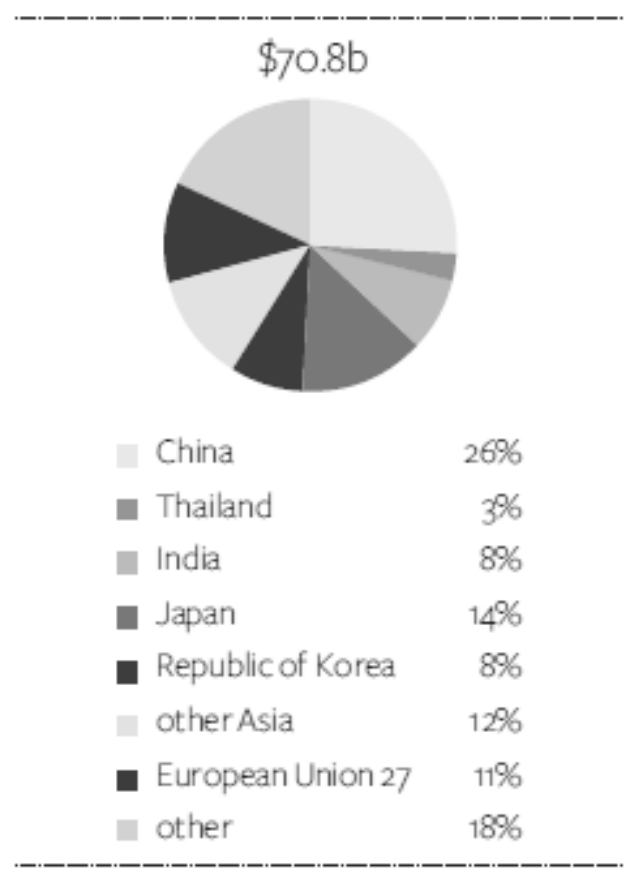


Figure 5 - Western Australian Commodities (WA DMP, 2008)

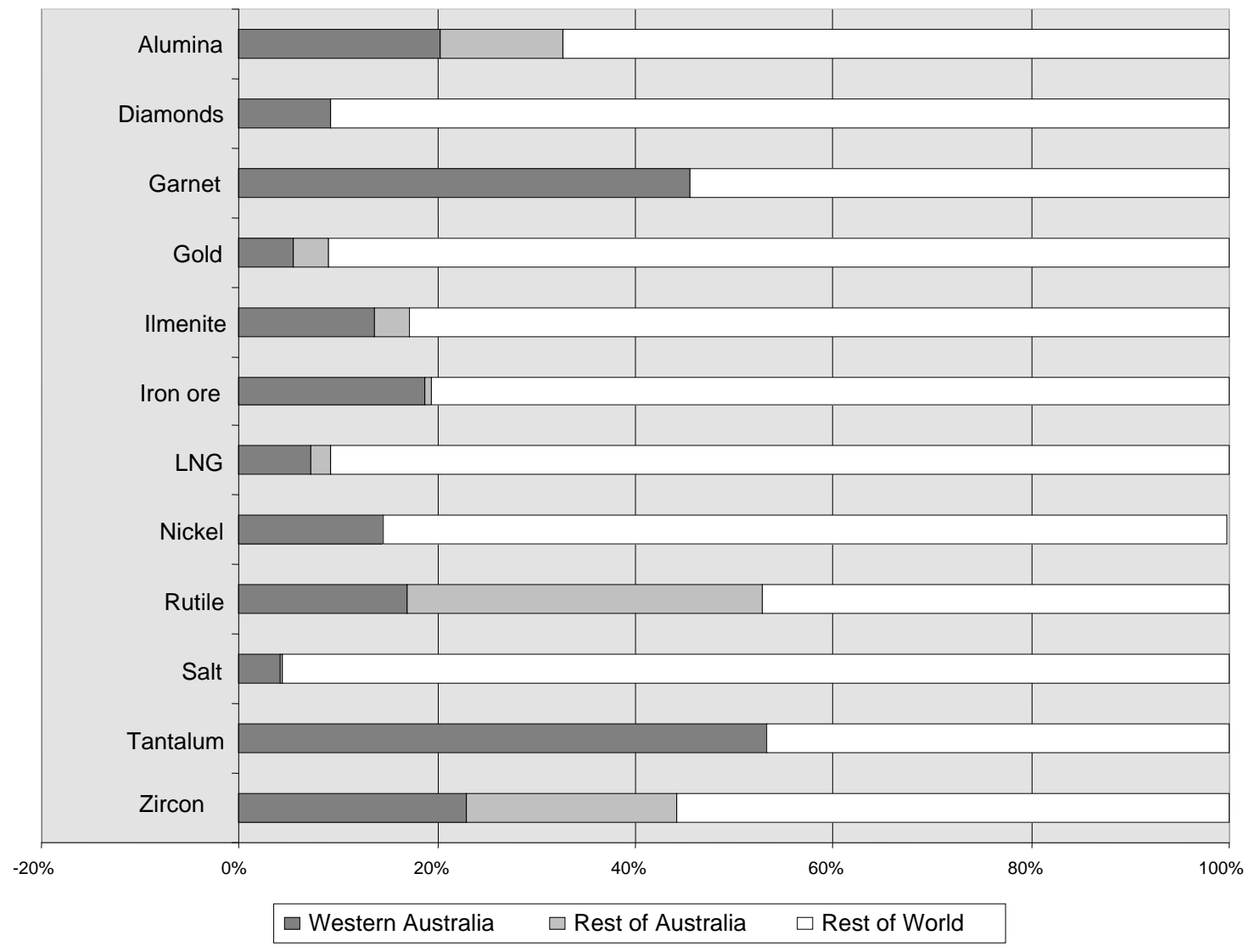

